Research Article

\title{
Computer Aided Drug Screening for Lung Infection
}

\author{
Joydeep Paul*1, Payel Debnath ${ }^{1}$, Ranajit Nath ${ }^{1}$, Ratul Bhowmik², Sara Farheen ${ }^{1}$ \\ 1. Department of Pharmacology, NSHM Knowledge Campus, Kolkata-Group of Institutions, Kolkata, West Bengal, India. \\ 2. Department of Pharmaceutical Chemistry, SPER, Jamia Hamdard, New Delhi, India. \\ *Corresponding author's E-mail: bkwatra999@gmail.com
}

Received: 02-03-2021; Revised: 22-04-2021; Accepted: 28-04-2021; Published on: 15-05-2021.

\begin{abstract}
Lung infections are the leading cause of morbidity and mortality worldwide. Most causes of infection are not treatable. In children less than 5 years of age, they are the cause of death. Most infections are caused by viruses and bacteria. We present a dockingscreening using a quantum mechanical scoring of a library built from approved drugs and competent that apiin, baicalein, boswellic acid, eugenol, ganoderic acid, quercetin, vasicine, with proteins with PDB id's 1VQQ, 3N26, 7K40, $5 E G 7$ could display antiviral activity against lung infection. Clearly, these compounds should be further evaluated and clinical trials to confirm their actual activity against the disease.
\end{abstract}

Keywords: Lung infection, phytochemicals, docking, active sites, ligand, receptor.

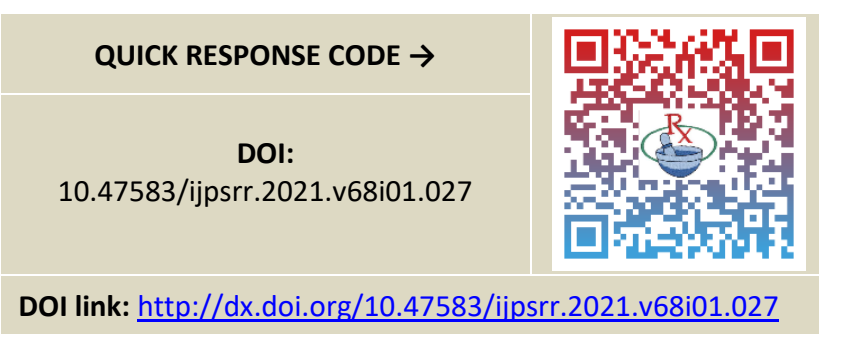

\section{INTRODUCTION}

ung infection is often considered one of the most common medical conditions around the globe. It is also considered as one of the leading causes of death and disability in the world. It is estimated that lung infection accounts for more than 4 million fatalities annually ${ }^{14}$. Bacteria and viruses are the main causes of acute lower respiratory tract infection. Therefore, there is a pressing need to create an intense enemy of this disease, specialist for the avoidance of the flare - up and stop the bacterial and viral contaminations. Repurposing of realized little particles is by all accounts an exceptionally productive path so as to create strong medications to battle diseases in this brief timeframe ${ }^{1-5,11,15,16,21,24,26}$. As of late, various endeavors are made to plan novel inhibitors or utilize drug repurposing ways to deal with recognition hostile to medication ${ }^{10,12,18}$.

\section{PROCEDURE}

\section{Ligand Screening}

For the initial Ligand screening purposes, a web-based tool named SwissADME ( https ://www.swiss adme.ch/) was used to eliminate a few compounds according to Lipinski's rule of five parameters ${ }^{23}$. For a compound to qualify as ligand it should Have < 500 Da molecular weight, a high lipophilicity i.e. value of Log $\mathrm{P}$ being less than 5 , hydrogen bond acceptors being less than 10 and $\mathrm{H}$-bond donors less than 5 . Any compound with more than 2 violations was ruled out for further study.

\section{Protein Preparation and Active Site Determination.}

Required protein in pdb format was downloaded from the website rcsb.org, commonly known as the Protein Data Bank ${ }^{28}$. 3D conformers of the ligand were downloaded from PubChem ${ }^{19,20}$.

Using PyMOL (Version 2.4.1) software water molecules as well as native ligands from the protein were removed, defined as cleaning/purification of the protein for further application ${ }^{29}$. Using a web server called Deep Site Active Pockets of the proteins were calculated ${ }^{8}$. The results calculated by the web server were in the form of different ids, centers and scores.

Scoring in deep site was using neural networking based on following instructions using DCNN architecture. Center values for the grid were selected keeping score greater than 0.98 .

UCSF Chimera (Version 1.14) was used to prepare the receptor using DockPrep function ${ }^{30}$. Dock Prep prepared structures for Docking using these functions:

- deleting water molecules

- repairing truncated sidechains

- adding hydrogens

- assigning partial charges

- writing files in Mol2 format

In silico Docking Using Auto dock Vina Autodock Vina (Version 1.1.2) along with UCSF Chimera (Version 1.14) was used for molecular Docking Studies ${ }^{6,30}$. Center values 
and size of the grid of different scores were used from DEEPSITE calculations done above.

Following Parameters were set in auto dock vina.

\section{Receptor options -}

- Add hydrogens in Chimera (true/false) - whether to add hydrogens in Chimera before calling the script. The receptor prep script will check for hydrogens and add them if they are missing. AutoDock Vina needs the polar (potentially $\mathrm{H}$-bonding) hydrogens to identify atom types for scoring purposes.

- Merge charges and remove non-polar hydrogens (true/false) - note AutoDock Vina does not use charges or nonpolar hydrogens, so this setting is not expected to affect results except for the presence or absence of nonpolar hydrogens in the processed receptor

- Merge charges and remove lone pairs (true/false) note AutoDock Vina does not use charges or lone pairs, so this setting is not expected to affect results except for the presence or absence of lone pairs in the processed receptor (and there may not have been any lone pairs to start with)

- Ignore waters (true/false)

- Ignore chains of non-standard residues (true/false) - ignore chains composed entirely of residues other than the 20 standard amino acids.

- Ignore all non-standard residues (true/false) ignore all residues other than the 20 standard amino acids.

\section{For Ligands}

- Merge charges and remove non-polar hydrogens (true/false) - note Auto Dock Vina does not use charges or nonpolar hydrogens, so this setting is not expected to affect results except for the presence or absence of nonpolar hydrogens in the ligand output files

- Merge charges and remove lone pairs (true/false) note AutoDock Vina does not use charges or lone pairs, so this setting is not expected to affect results except for the presence or absence of lone pairs in the ligand output files (and there may not have been any lone pairs to start with)

\section{Docking parameters}

- Number of binding modes $(1-10,10)$ - maximum number of binding modes to generate

- Exhaustiveness of search (1-8, 8) - thoroughness of search, roughly proportional to time

- Maximum energy difference ( $\mathrm{kcal} / \mathrm{mol})(1-3,3)-$ maximum score range; binding modes with scores not within this range of the best score will be discarded.
The docking results were calculated by Auto dock vina using it's Scoring function and results were displayed in the form of Scores and RMSD values. Docking results with the highest value score accompanied by negative sign and least RMSD values were chosen for further studies.

\section{Residue Analysis}

PyMOL was used for visualization of interactions of the docked structure at the ligand sites. Discovery Studio 2020 was used to study the ligand interactions and total number of residues ${ }^{7}$. It was also used to plot the $2 \mathrm{D}$ structure of the interactions and residues.

\section{Statistical Analysis}

Descriptive, estimation and Hypothesis testing with confidence interval of $95 \%$ was applied to data using formula 1 given belw.

$$
\begin{aligned}
& \qquad I=\bar{x} \pm z \frac{s}{\sqrt{n}} \\
& C I=\text { confidence interval } \\
& \bar{x}=\text { sample mean } \\
& z=\text { confidence level value } \\
& s \quad=\text { sample standard deviation } \\
& n=\text { sample size }
\end{aligned}
$$

Formula 1 used for calculation of confidence interval

\section{RESULTS AND DISCUSSION}

\section{Molecular Docking}

The docking result was obtained from Autodock vina in the form of Dock score for all the four proteins docked with the above mentioned ligands.

\section{Docking Results of Influenza Virus Protein}

\section{PDB-ID 5EG7 25,26,27}

For 5EG7, two active sites were selected out of which the first active site was selected with a Deepsite score of 0.99965. The selection was made on the basis of the highest binding energy of the ligand-receptor. The docking results before statistics are shown in Table 1 and Table 2 shows the post statistical docking scores with Ligand Protein interactions.

Table 1: Docking score of phytochemicals with Influenza Virus viral protein.

\begin{tabular}{|c|c|}
\hline Ligand & Dockscore \\
\hline Apiin & -8 \\
\hline Baicalein & -8 \\
\hline Boswelic Acid & -7.6 \\
\hline Eugenol & -5.8 \\
\hline Genoderic Acid & -7.2 \\
\hline Quercetin & -8.2 \\
\hline Resveratrol & -7.2 \\
\hline Vasicine & -6.3 \\
\hline
\end{tabular}


Table 2: Docking scores and 2D amino acids interactions of Apiin, Baicalein and Quercetin with Influenza Virus viral protein.

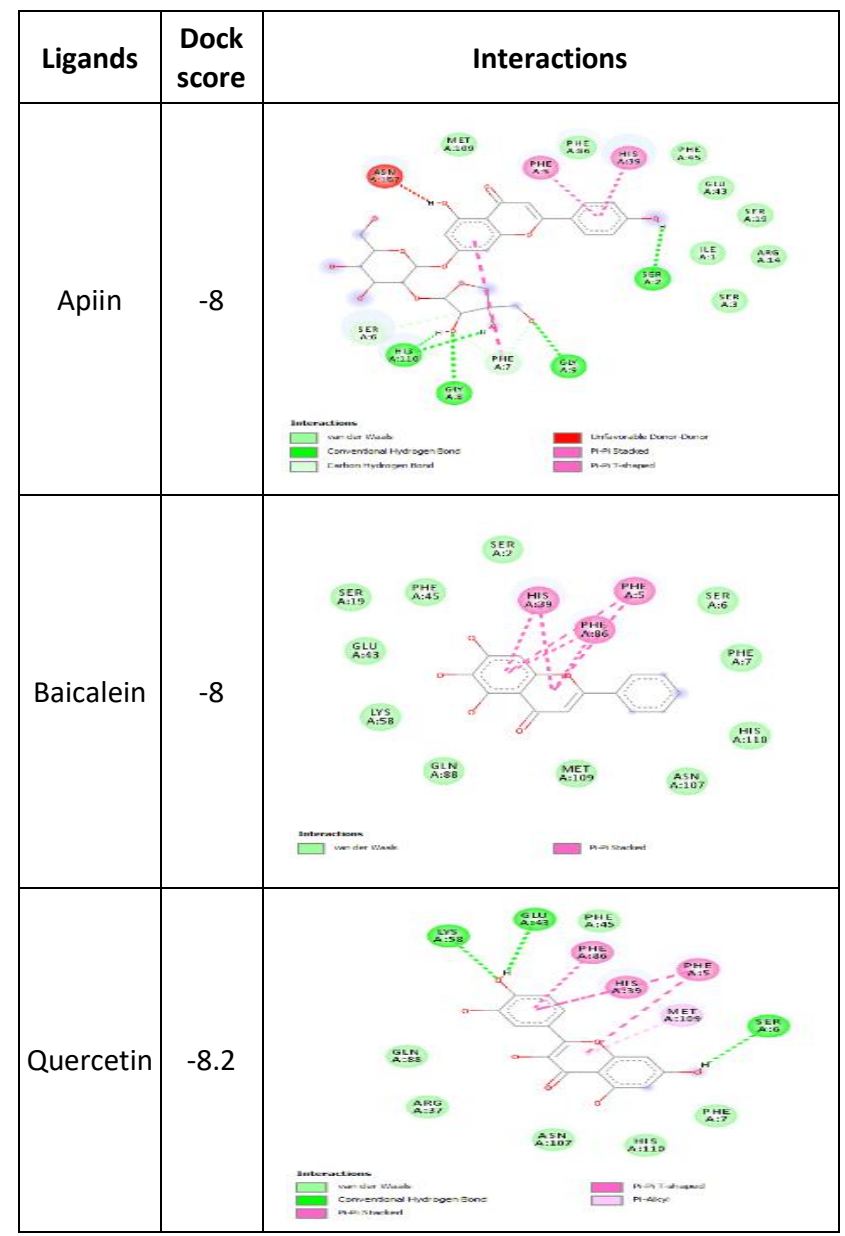

Docking results of SARS-Cov2 viral protein

\section{PDB-ID 7K40 ${ }^{9}$}

For $7 \mathrm{~K} 40$, four active sites were selected out of which the second active site was selected with a Deepsite score of 0.988627 . The selection was made on the basis of the highest binding energy of the ligand-receptor. The docking results before statistics are shown in Table $\mathbf{3}$ and Table $\mathbf{4}$ shows the post statistical docking score with Ligand Protein interactions.

Table 3: Docking score of phytochemicals with SARS-CoV2 viral protein.

\begin{tabular}{|c|c|}
\hline Ligand & Dockscore \\
\hline Vasicine & -5.5 \\
\hline Eugenol & -5.3 \\
\hline Apiin & -8.9 \\
\hline Baicalein & -6.8 \\
\hline Resveratrol & -7.6 \\
\hline Quercetin & -7.9 \\
\hline Ganoderic Acid & -7.6 \\
\hline Boswellic Acid & -7.5 \\
\hline
\end{tabular}

Table 4: Docking scores and 2D amino acids interactions of Apiin and Quercetin with SARS-CoV2 viral protein.

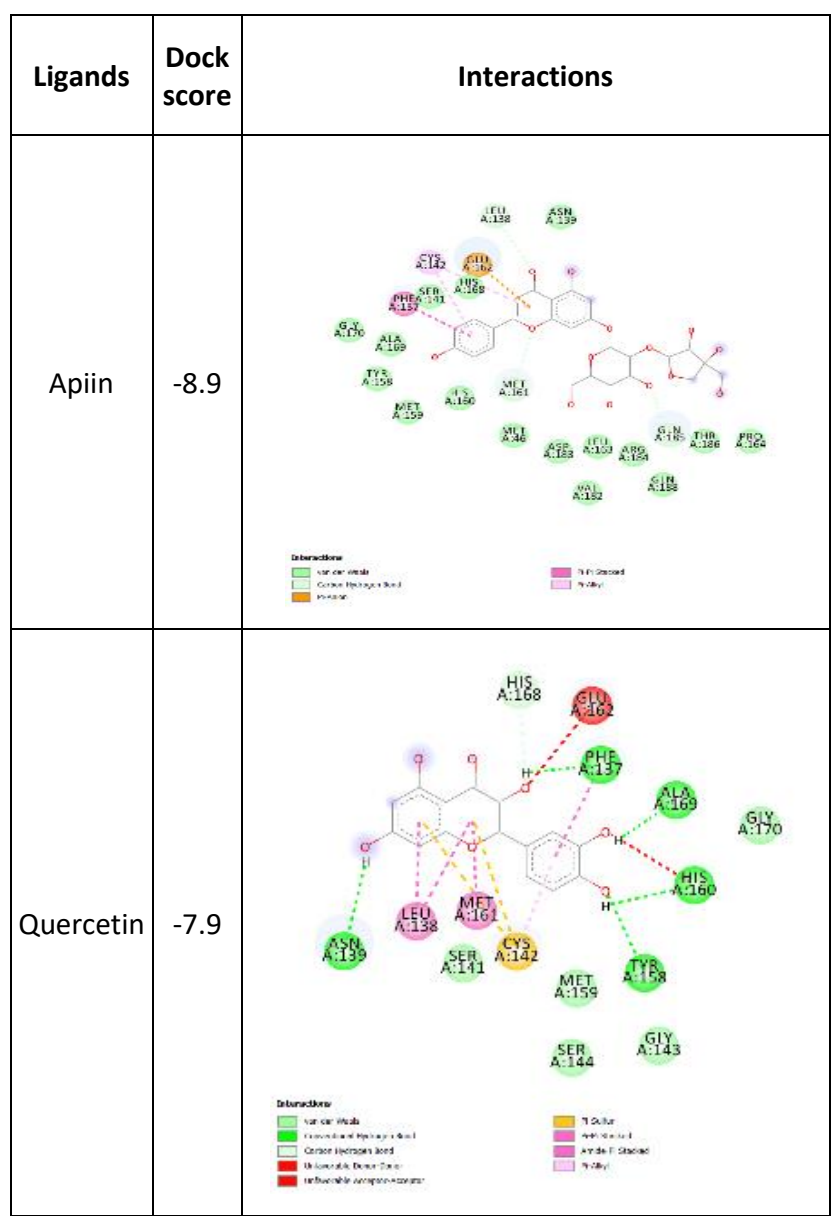

Docking results of Chlamydia pneumoniae transport protein

\section{PDB-ID 3 N26 ${ }^{13}$}

For 3N26, four active sites were selected out of which the first active site was selected with a Deepsite score of 0.999139 . The selection was made on the basis of the highest binding energy of the ligand-receptor. The docking results before statistics are shown in Table 5 and Table 6 shows the post statistical docking score with Ligand Protein interactions.

Table 5: Docking score of phytochemicals with Chlamydia pneumoniae transport protein.

\begin{tabular}{|c|c|}
\hline Ligand & Dock score \\
\hline Eugenol & -5.2 \\
\hline Vasicine & -5.4 \\
\hline Apiin & -8.4 \\
\hline Baicalein & -6.8 \\
\hline Boswellic Acid & -6.9 \\
\hline Ganoderic Acid & -6.7 \\
\hline Quercetin & -6.9 \\
\hline Resveratrol & -6.8 \\
\hline
\end{tabular}


Table 6: Docking scores and 2D amino acids interactions of Apiin with Chlamydia pneumoniae transport protein.

\begin{tabular}{|c|c|c|}
\hline Ligands & $\begin{array}{l}\text { Dock } \\
\text { Score }\end{array}$ & Interactions \\
\hline Apiin & -8.4 & (E) \\
\hline
\end{tabular}

Docking results of Staphylococcus aureus penicillin binding protein

PDB-ID 1VQQ ${ }^{17,25}$

For $1 \mathrm{VQQ}, 2$ active sites for chain $\mathrm{A}$ and 2 active sites for chain $B$ were selected out of which the first active site of chain B was selected with a Deepsite score of 0.998654 . The selection was made on the basis of the highest binding energy of the ligand-receptor. The docking results before statistics are shown in Table $\mathbf{7}$ and Table $\mathbf{8}$ shows the post statistical docking score with Ligand Protein interactions.

Table 7: Docking score of phytochemicals with Staphylococcus aureus penicillin binding protein.

\begin{tabular}{|c|c|}
\hline Ligand & Dock score \\
\hline Apiin & -8.7 \\
\hline Baicalein & -7.8 \\
\hline Boswellic Acid & -10 \\
\hline Eugenol & -5.4 \\
\hline Genoderic Acid & -7.1 \\
\hline Quercetin & -7.6 \\
\hline Resveratrol & -7.2 \\
\hline Vasicine & -6.1 \\
\hline
\end{tabular}

Table 8: Docking scores and 2D amino acids interactions of Apiin and Boswellic acid with Staphylococcus aureus penicillin binding protein.

\begin{tabular}{|c|c|c|}
\hline Ligands & $\begin{array}{c}\text { Dock } \\
\text { score }\end{array}$ & Interactions \\
\hline \multirow{3}{*}{ Apiin } & -8.7 & \\
& & \\
& & \\
& & \\
\hline
\end{tabular}

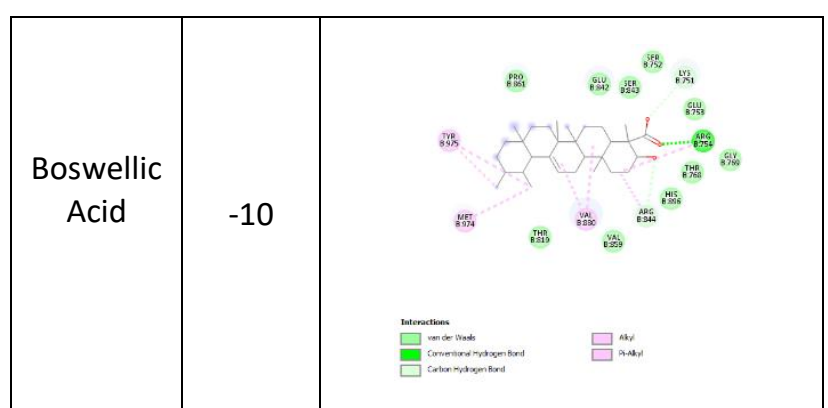

Table 9: It summarizes the results showing ligands and their interacted proteins that were considered in the study for the targeted disease.

\begin{tabular}{|c|c|c|}
\hline Ligands & $\begin{array}{c}\text { Proteins } \\
\text { Interacted }\end{array}$ & Target Disease \\
\hline $\begin{array}{c}\text { Apiin } \\
\text { Baicalein } \\
\text { Boswellic acid } \\
\text { Eugenol } \\
\text { Ganoderic acid } \\
\text { Quercetin } \\
\text { Resveratrol } \\
\text { Vasicine }\end{array}$ & $\begin{array}{c}1 \mathrm{VQQ} \\
7 \mathrm{~K} 40 \\
3 \mathrm{~N} 26 \\
5 \mathrm{EG} 7\end{array}$ & $\begin{array}{l}\text { Lung infection caused by } \\
\text { Sars-CoV2 (7K40), } \\
\text { Influenza Virus (5EG7), } \\
\text { Staphylococcus aureus } \\
\text { (1VQQ), Chlamydia } \\
\text { pneumonia (3N26) }\end{array}$ \\
\hline
\end{tabular}

\section{CONCLUSION}

All 8 ligands were studied using bioavailability radar. Our results proposed that Apiin, Baicalein and Quercetin showed best docking results with PDB-ID 5EG7. For PDB-ID 7K40, Apiin and Quercetin showed the best docking results. Apiin also showed best docking results with PDBID 3N26. For PDB-ID 1VQQ, Apiin and Boswellic acid showed best docking results. To find the effectiveness and to propose the exact mechanism in-vitro studies can be encouraged on Apiin, Baicalein, Quercetin, and Boswellic acid targeting their respective protein of organisms responsible for lung infection that are discussed above to understand the mechanism and a potential cure for lung infection.

\section{Acknowledgement}

We would like to thank our supervisor, Bharat Kwatra, from Invenzion Labs Inc. whose expertise was invaluable in formulating the research questions, methodology and drawing conclusions. His insightful feedback and guidance pushed us to sharpen our thinking and brought our work to a higher level.

\section{REFERENCES}

1. Mencherini T, Cau A, Bianco G, Loggia R Della, Aquino RP, Autore G. An extract of Apium graveolens var. dulce leaves: structure of the major constituent, apiin, and its anti-inflammatory properties. J Pharm Pharmacol. 2007;59(6):891-897.

2. Marchese A, Barbieri R, Coppo E, Orhan IE, Daglia M, Nabavi SF, et al. Antimicrobial activity of eugenol and essential oils containing eugenol: A mechanistic viewpoint. Vol. 43, Critical Reviews in Microbiology. 2017. p. 688-699. 
3. Duraipandiyan V, Al-Dhabi NA, Balachandran C, Ignacimuthu S, Sankar C, Balakrishna K. Antimicrobial, antioxidant, and cytotoxic properties of Vasicine acetate synthesized from Vasicine isolated from adhatoda vasica I. Biomed Res Int. 2015;2015:1-7.

4. Gill BS, Navgeet, Kumar S. Antioxidant potential of ganoderic acid in Notch-1 protein in neuroblastoma. Mol Cell Biochem. 2019;456(12):1-14.

5. Zhang S, Wang D, Huang J, Hu Y, Xu Y. Application of capsaicin as a potential new therapeutic drug in human cancers. Vol. 45 , Journal of Clinical Pharmacy and Therapeutics. 2020. p. 16-28.

6. Trott O, Olson AJ. AutoDock Vina: Improving the speed and accuracy of docking with a new scoring function, efficient optimization, and multithreading. J Comput Chem. 2009;31(2):455-61.

7. Accelrys Inc. BIOVIA Materials Studio. Http://AccelrysCom/. 2017;

8. Jiménez J, Doerr S, Martínez-Rosell G, Rose AS, De Fabritiis G. DeepSite: Protein-binding site predictor using 3D-convolutional neural networks. Bioinformatics. 2017;33(19):3036-3042.

9. Hoffman RL, Kania RS, Brothers MA, Davies JF, Ferre RA, Gajiwala $\mathrm{KS}$, et al. Discovery of Ketone-Based Covalent Inhibitors of Coronavirus $3 \mathrm{CL}$ Proteases for the Potential Therapeutic Treatment of COVID-19. J Med Chem. 2020;63(21):12725-12747.

10. Kwatra B, Roy R, Bhowmik R, Sengupta S. DRUG REPURPOSING : IN SILICO MODELING OF COVID-19. Res J Life Sci Bioinformatics, Pharm Chem Sci. 2021;7(2):19-40.

11. Vijayarani KR, Govindarajulu M, Ramesh S, Alturki M, Majrashi M, Fujihashi A, et al. Enhanced Bioavailability of Boswellic Acid by Piper longum: A Computational and Pharmacokinetic Study. Front Pharmacol. 2020;11:1-8.

12. Vetting MW, Al-Obaidi N, Zhao S, San Francisco B, Kim J, Wichelecki DJ, et al. Experimental strategies for functional annotation and metabolism discovery: Targeted screening of solute binding proteins and unbiased panning of metabolomes. Biochemistry. 2015;54(3):909-931.

13. Soriani $M$, Petit $P$, Grifantini R, Petracca $R$, Gancitano $G$, Frigimelica $E$, et al. Exploiting antigenic diversity for vaccine design: The chlamydia ArtJ paradigm. J Biol Chem. 2010;285(39):30126-38.

14. Disler RT, Gallagher RD, Davidson PM, Sun S-W, Chen L-C, Zhou M, et al. Factors impairing the postural balance in COPD patients and its influence upon activities of daily living. Eur Respir J. 2019;15(1).

15. Cao FR, Feng L, Ye LH, Wang LS, Xiao BX, Tao X, et al. Ganoderic Acid A Metabolites and Their Metabolic Kinetics. Front Pharmacol. 2017;8(MAR):1-13.

16. Gill BS, Navgeet, Mehra R, Kumar V, Kumar S. Ganoderic acid, lanostanoid triterpene: a key player in apoptosis. Vol. 36, Investigational New Drugs. 2018. p. 136-43.
17. Harrison EM, Ba X, Coll F, Blane B, Restif O, Carvell H, et al. Genomic identification of cryptic susceptibility to penicillins and $\beta$-lactamase inhibitors in methicillin-resistant Staphylococcus aureus. Nat Microbiol. 2019;4(10):1680-1691.

18. Kwatra B, Khatun A, Bhowmik R, Rehman S. In silico-modelling of phytochemicals in septic arthritis. Pharma Innov. 2021;10(3):14-21.

19. Kim S, Chen J, Cheng T, Gindulyte A, He J, He S, et al. PubChem 2019 update: improved access to chemical data. Nucleic Acids Res. 2019;47(D1):D1102-D1109.

20. Kim S, Thiessen PA, Bolton EE, Chen J, Fu G, Gindulyte A, et al. PubChem substance and compound databases. Nucleic Acids Res. 2016;44(D1):D1202-13.

21. Salehi B, Mishra AP, Nigam M, Sener B, Kilic M, Sharifi-Rad M, et al. Resveratrol: A double-edged sword in health benefits. Vol. 6, Biomedicines. 2018. p. 1-20.

22. Morris GM, Ruth H, Lindstrom W, Sanner MF, Belew RK, Goodsell DS, et al. Software news and updates AutoDock4 and AutoDockTools4: Automated docking with selective receptor flexibility. J Comput Chem. 2009;30(16):2785-91.

23. Daina A, Michielin O, Zoete V. SwissADME: A free web tool to evaluate pharmacokinetics, drug-likeness and medicinal chemistry friendliness of small molecules. Sci Rep. 2017;7.

24. Shamraiz U, Hussain H, Ur Rehman N, Al-Shidhani S, Saeed A, Khan $\mathrm{HY}$, et al. Synthesis of new boswellic acid derivatives as potential antiproliferative agents. Nat Prod Res. 2020;34(13):1845-52.

25. Severin C, De Moura TR, Liu Y, Li K, Zheng X, Luo M. The cap-binding site of influenza virus protein PB2 as a drug target. Acta Crystallogr Sect D Struct Biol. 2016;72(2):245-53.

26. Priyadarsini KI. The chemistry of curcumin: From extraction to therapeutic agent. Vol. 19, Molecules. 2014. p. 20091-112.

27. Nelson KM, Dahlin JL, Bisson J, Graham J, Pauli GF, Walters MA. The Essential Medicinal Chemistry of Curcumin. J Med Chem. 2017;60(5):1620-37.

28. Berman HM, Battistuz T, Bhat TN, Bluhm WF, Bourne PE, Burkhardt $\mathrm{K}$, et al. The protein data bank. Acta Crystallogr Sect D Biol Crystallogr. 2002;58(6-1):899-907.

29. DeLano WL. The PyMOL Molecular Graphics System, Version 2.3. Schrödinger LLC. 2020.

30. Pettersen EF, Goddard TD, Huang CC, Couch GS, Greenblatt DM, Meng EC, et al. UCSF Chimera - A visualization system for exploratory research and analysis. J Comput Chem. 2004;25(13):1605-11.

Source of Support: None declared.

Conflict of Interest: None declared.

For any question relates to this article, please reach us at: editor@globalresearchonline.net

New manuscripts for publication can be submitted at: submit@globalresearchonline.net and submit_ijpsrr@rediffmail.com 